www.jmscr.igmpublication.org

Index Copernicus Value: 79.54

ISSN (e)-2347-176x ISSN (p) 2455-0450

crossrefDOI: https://dx.doi.org/10.18535/jmscr/v7i3.176

\title{
Profile of infraorbital zygomatic fractures with comparison between subciliary and subtarsal incisions in their management
}

\author{
Authors
}

Shahnawaz Rasool, Mudasir Habib, Samar Mukhtar, Ishfaq A Parrah

\begin{abstract}
Introduction: The occurrence of facial fractures has increased especially in young population .The surgical management of infraorbital zygomatic fractures is very complex because of their functional and aesthetic implications. Their management not only demands the restoration of function but also the cosmetic appearance.

Aims: To see the demographic profile of infra orbital zygomatic fractures and to compare subciliary and subtarsal incisions in the management of them on the basis of time taken, exposure achieved and the aesthetic outcome.

Methods: This prospective study was conducted in the Department of Plastic and Reconstructive Surgery SKIMS, Srinagar. The study included a total of 50 patients. The patients were divided into two groups randomly. In 25 patients subciliary approach was used and in 25 subtarsal.

Results: Majority (60\%) of patients were in the age group of 16-30 years, $78 \%$ of patients were males and $22 \%$ patients were females. Time taken was higher in subciliary group (16-20 minutes in 64\% patients). Exposure achieved was better in subtarsal incision group (Excellent in 80\%). The incidence of transient ectropion was higher in subciliary group (8\%) while the incidence of lower lid edema (4\%) and noticeable scar(4\%) was more in subtarsal group.

Conclusion: We found the subciliary incision having better cosmetic results. However more prospective studies with large number of cases are needed to make definitve conclusions.

Keywords: infraorbital, zygomatic fractures, subciliary, sub tarsal, aesthetic.
\end{abstract}

\section{Introduction}

Facial injuries are one of the most challenging injuries due to their functional and aesthetic implications. Sometimes restoration of external appearance may be the only indication for surgical intervention which makes the management of facial injuries unique. Zygomatico-maxillary fractures are second only to nasal fractures as the commonest type of facial fractures. Zygomatic complex fractures comprise $31.69 \%$ of all facial fractures. (1) Although the zygoma is a sturdy bone, it is frequently injured because of its prominent location. Knight and North ${ }^{(2)}$ proposed a classification system in 1961 for zygomatic fractures based on the direction of displacement and the pattern formed by the fracture. Zygomatic fractures usually occur due to road traffic accidents, falls or assaults. The direction and 
amount of displacement and degree of comminution determine the plan of treatment. Open reduction and internal fixation is the preferred method of treatment. Several incisions have been reported to approach the infraorbital rim and orbital floor, such as the subtarsal, the subciliary, the trans-conjunctival and the infraorbital incisions, in addition to the newly described endoscopically assisted intraoral approach. Despite a recent surge in the popularity of transconjunctival incision, periorbital surgery by a cutaneous approach is a valid means of access for a variety of procedures. A cutaneous approach spares the conjunctiva, bypasses the tansconjunctival related complications. A proper understanding of each incisional technique requires an appreciation of the relevant anatomy and the risk of associated complications. Each of these approaches has its advantages and disadvantages that may make it more or less appealing to use depending on the patient's age and severity of fracture.

\section{Aims}

1. To see the demographic profile of infraorbital zygomatic fractures.

2. To compare subciliary and sub tarsal incisions for management of infraorbital zygomatic fractures with respect to aesthetic outcome, surgical exposure achieved and time taken to approach the fracture.

\section{Methods}

It was a prospective study and comprised of the patients who underwent treatment for infraorbital zygomatic fractures from Dec 2011 to August 2013 in the department of plastic and reconstructive surgery SKIMS, Srinagar. After taking a detailed history, clinical examination was done. Investigations included complete hemogram, blood grouping, kidney function test, NCCT face with $2 \mathrm{~mm}$ axial and coronal cuts with 3D reconstruction. Patients were divided into two groups, viz. subciliary incision group and subtarsal incision group. An equal number of patients were allocated randomly into each group by systematic random sampling. The follow up information was obtained prospectively by following these patients in the outpatient clinic for 6 months. The study comprised of 50 patients who had infraorbital zygomatic fractures and were subsequently subjected to open reduction and internal fixation. In 25 patients subciliary approach was used and in 25 patients subtarsal approach. Only patients with age more than 16 years were included in the study.

The subciliary incision was placed about $2 \mathrm{~mm}$ caudal to the ciliary line. Dissection was done in a stepped skin-muscle flap fashion, keeping the pretarsal fibers of the orbicularis muscle attached to the tarsal plate.

The subtarsal incision was placed about 5 to 7 $\mathrm{mm}$ below and parallel to the ciliary margin. In both the approaches after fixation of fracture with titanium miniplates, a 5-0 absorbable vicryl suture was used to re-approximate the orbicularis muscle. The skin was approximated by 5-0 prolene continuous suture. The results were presented as mean \pm standard deviation and percentages. Moreover, at many places Fisher's Exact Test has been used to see the association between two variables. Statistical Package SPSS version 20 was used for data analysis. 


\section{Results}

Following observations were drawn from the study:

Table 1: Age and sex distribution of cases

\begin{tabular}{|l|c|c|c|c|c|c|}
\hline \multirow{2}{*}{ Age(yrs) } & \multicolumn{2}{|c|}{ Males } & \multicolumn{2}{c|}{ Females } & \multicolumn{2}{c|}{ Total } \\
\cline { 2 - 7 } & No. & \%age & No. & \%age & No. & \%age \\
\hline 16-30 & 23 & 46 & 7 & 14 & 30 & 60 \\
\hline 31-50 & 13 & 26 & 4 & 8 & 17 & 34 \\
\hline Total and Above & 3 & 6 & 0 & 0 & 3 & 6 \\
\hline
\end{tabular}

It was observed $60 \%$ of patients were in the age group of $16-30$ years, $34 \%$ in the age group of 31 50 years, and $6 \%$ patients were above 51 years.
$78 \%$ of patients were males and $22 \%$ patients were females.

Table 2: Causes of infraorbital zygomatic fractures

\begin{tabular}{|l|c|c|}
\hline Cause & No of patients & Percentage (\%) \\
\hline Road traffic accidents & 38 & 76 \\
\hline Falls & 10 & 20 \\
\hline Assaults & 2 & 4 \\
\hline Total & 50 & 100 \\
\hline
\end{tabular}

Most common cause was road traffic accidents in $76 \%$ of patients followed by falls in $20 \%$ and assaults in $4 \%$ cases.

Table 3: Associated injuries in the patients

\begin{tabular}{|l|c|c|}
\hline Type of Injury & No of Patients & Percentage (\%) \\
\hline Neurosurgical injuries & 7 & 14 \\
\hline Long bone fractures & 3 & 6 \\
\hline Chest, abdomen injuries & 2 & 4 \\
\hline No associated injury & 40 & 80 \\
\hline
\end{tabular}

Associated injury was present in $20 \%$ patients.

Most common associated injuries were bone fractures in $6 \%$ and chest, abdomen injuries neurosurgical in $14 \%$ of patients followed by long

Table 4: Clinical features of infraorbital-zygomatic fractures

\begin{tabular}{|l|c|c|}
\hline Clinical Table feature & No of patients & Percentage (\%) \\
\hline Ecchymosis & 48 & 96 \\
\hline Pain & 45 & 90 \\
\hline Stepping & 50 & 100 \\
\hline Subconjunctival hemorrhage & 34 & 68 \\
\hline Infraorbital hypo-aesthesia & 25 & 50 \\
\hline
\end{tabular}

Most common clinical features were stepping in $100 \%$ followed by ecchymosis in $96 \%$ of patients, pain in $90 \%$, subconjunctival hemorrhage

Table 5: Time taken to approach the fracture

\begin{tabular}{|l|c|c|c|}
\hline \multirow{2}{*}{ Type of Incision } & \multicolumn{3}{|c|}{ Time taken to approach the facture } \\
\cline { 2 - 4 } & $12-15 \mathrm{mins}$ & $16-20 \mathrm{mins}$ & $>21 \mathrm{mins}$ \\
\hline Subciliary & $7(28 \%)$ & $16(64 \%)$ & $2(8 \%)$ \\
\hline Sub Tarsal & $17(68 \%)$ & $7(28 \%)$ & $1(4 \%)$ \\
\hline P value: 0.011 & \multicolumn{3}{|l}{} \\
\hline
\end{tabular}


In $17(68 \%)$ of subtarsal incisions time taken was in 12-15 minute range whereas in $16(64 \%)$ of subciliary incisions time taken was in 16-20 minute range.

Table 6: Extent of exposure

\begin{tabular}{|l|c|c|c|}
\hline Type of incision & Excellent & Good & Poor \\
\hline Subciliary & $18(72 \%)$ & $5(20 \%)$ & $2(8 \%)$ \\
\hline Subtarsal & $20(80 \%)$ & $4(16 \%)$ & $1(4 \%)$ \\
\hline P value: 0.789 & & & \\
\hline
\end{tabular}

In $20(80 \%)$ of subtarsal incisions the exposure achieved was excellent compared to $18(72 \%)$ in
This time difference was statistically significant.

Table 7: Complications

\begin{tabular}{|l|c|c|c|}
\hline Type of Incision & Ectropion & Grossly visible scar & Edema \\
\hline Subciliary & $2(8 \%)$ & 0 & 0 \\
\hline Sub Tarsal & 0 & $1(4 \%)$ & $1(4 \%)$ \\
\hline
\end{tabular}

$2(8 \%)$ patients in subciliary group developed ectropion compared to $0 \%$ in subtarsal group. Difference was statistically insignificant.

In $1(4 \%)$ of subtarsal incisions grossly visible scar was seen compared to $0 \%$ in subciliary group. $1(4 \%)$ case lid edema was seen in subtarsal group compared to $0 \%$ in subciliary group. The difference was statistically insignificant.

\section{Discussion}

Most of the patients (60\%) in our study were in the age group 16-30 years which is similar to that of Wray RC et al ${ }^{(3)} \&$ Bahr W et al. ${ }^{(4)}$

Majority of the patients in our study $(78 \%)$ were males which is similar to that of Wray RC et al $(76 \%)^{(3)}$, Crosara JM $(65 \%){ }^{(5)}$ and Giraddi GB $(95 \%){ }^{(6)}$

In our study the most common cause of injuries was road traffic accidents (76\%) followed by falls $(20 \%)$ and assaults (4\%). It is similar to the study conducted by Tung et al ${ }^{(7)}$ in which the most common cause of injury was road traffic accidents followed by falls. Patients with infraorbital zygomatic fractures can present with multiple associated injuries. In our study $10(20 \%)$ patients were having associated injuries. The most common associated injury was neurosurgical in 7 (14\%) patients. Our results are consistent with that of Lim et al ${ }^{(8)}$ who reported an $11.3 \%$ rate of associated injuries with neurosurgical trauma being the most common. The more direct the approach, the more rapid the exposure of fracture. In our study the time taken to approach the fracture via the subciliary incision was more (18 minutes) than that of subtarsal incision (12.5 minutes) $\mathrm{p}<0.05$. This is slightly more than that found by Subrahmanian B et al (10 minutes for subtarsal approach \& 14 minutes for subciliary approach) ${ }^{(9)}$ and Wray RC et al ${ }^{(3)}$ (8 minutes for subtarsal as well as subciliary approach). subtarsal as well as subciliary approach).

Exposure of the fracture site was excellent in $80 \%$, good in $16 \%$ and poor in $4 \%$ of subtarsal incisions compared to subciliary incisions in which it was excellent in $72 \%$, good in $20 \%$ and poor in $8 \%$. Although the results were insignificant $(\mathrm{p}$ value $>0.05)$ this shows that there is better exposure in subtarsal incision. The difference is because of the comparatively direct and easier access in subtarsal incision. The result is similar to Rohrich Heckler et al ${ }^{(10)}$ found $0 \%$ cases of hypertrophic scars in 154 subciliary incisions. The skin of the eyelid is thinner \& has finer texture than cheek skin and hence has the propensity to form scars aesthetically superior to those of cheek. So superior the incision in the lower lid, better is the scar formed. In our study ectropion was noted in 2 cases $(8 \%)$ in whom 
subciliary incision was used while as no patient developed ectropion in the subtarsal group. But the results were statistically insignificant. The results are similar to that reported by Bahr $\mathrm{W}$ et al (6.3\% in subciliary \& $1.1 \%$ in sub tarsal) ${ }^{(11)}$ and Ridgeway et al $(12 \%$ in subciliary \& $2.7 \%$ in subtarsal) ${ }^{(12)}$. Of the two cases only one patient required repair for ectropion showing that conservative line of management with taping and massage was generally effective. In our study chronic lid edema was found in 1 case $(4 \%)$ of subtarsal approach which didn't resolve even after six months of follow up and in no case of the subciliary approach, which is consistent with that found by Bahr $\mathrm{W}$ et al (1.1\% in subtarsal approach and none in subciliary approach) ${ }^{(11)}$ and Rohrich et al $(2.2 \%$ in subtarsal and none in subciliary approach). However, except for the time taken to approach the fracture $(p=0.01)$, in favour of subtarsal approach, the results obtained in our study were statistically insignificant because the number of cases was less. Although the superiority of one incision over another can't be clearly demonstrated, the use of subciliary incision is preferred because of a much better scar in it, as the patients are mostly concerned about the postoperative scar appearance over the face. The subciliary incision rarely leaves any noticeable scar, but it is associated with temporary lower eyelid retraction. Subtarsal incision on the other hand has higher incidence of chronic lid edema. In our experience the postoperative ectropion is much lesser due to large turnover of patients, the highly experienced surgeons and use of stepped skin-muscle flap dissection. Once surgeons get experienced with subciliary incisions there is not much difference in the time taken by the incision and exposure achieved. Above all in surgery what matters is outcome not time. However, it is necessary to carry out more prospective studies with larger number of patients in order to make definitive conclusions.

\section{Bibliography}

1. Menon S, Sinha R, Thapliyal G, and Bandyopadhyay $\mathrm{T}$ : Management of Zygomatic Complex Fractures in a Tertiary Hospital: A Retrospective Study; J Maxillofac Oral Surg. 2011 June; 10(2): 138-141.

2. Knight JS, North JF: The classification of malar fractures: an analysis of displacement as a guide to treatment, $\mathrm{Br} \mathbf{J}$ Plast Surgery 1961;13:315.4

3. Wray RC, Holtmann BN, Ribaudo JM, Keiter A, Weeks PM: A comparison of conjunctival and subciliary incisions for orbital fractures. Br J Plast Surg; 1977; 30:142.

4. Werther JR: Cutaneous approaches to the lower lid and orbit. J Oral Maxillofac Surg 1998; 56:60-65.

5. Crosara JM, Rosa ES, Silva MR :Comparison of cutaneus incisions to approach the infraorbital rim. Braz J Oral Sci 2009 8/(2):88-91

6. Giraddi GB, Syed MK; Preseptal transconjunctival vs. subciliary approach in treatment of infraorbital rim and floor fractures: Annals of Maxillofacial Surgery 2012; 2(2): 136-140.

7. Tung TC, Tseng WS, Chen CT, Lai JP, Chen YR: Acute life threatening injuries in facial fracture patients: a review of 1025 patients. J trauma 2000 49: 420-24

8. Lim LH, Lam LK, Moore MH, Trott JA, David DJ: Associated injuries in facial fractures: review of 839 patients. $\mathrm{Br} \mathrm{J}$ Plast Surg 1993; 46: 635-38.

9. Subrahmanian B, Krishnamurthy S, Kumar S, Saravanan B, Padhmanabhan M: comparison of various approaches for exposure of infraorbital rim fractures of zygoma. J Maxillofac Oral Surg 8(2):99102.

10. Heckler FR, Songcharoen S, Sultani FA. Subciliary incision and skin-muscle 
eyelid flap for orbital fractures. Ann Plast Surg. 1983;10:309-313

11. Bahr W, Bagambisa FB, Schlegel G, and Schilli W: Comparison of transcutaneous incisions used for exposure of infraorbital rim and orbital floor: a retrospective study. Plast. Reconstr. Surg. 1992; 90: 585.

12. Rohrich RJ, Hollier I, Watumul D :Optimizing the management of orbitozygomatic fractures. Clin. Plast. Surg 1992; 19: 149. 